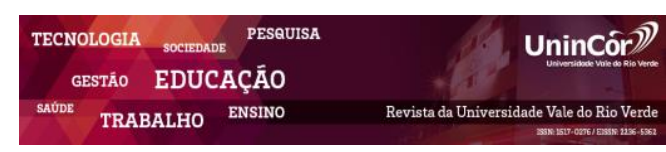

Revista da Universidade Vale do Rio Verde ISSN: 1517-0276 / EISSN: 2236-5362 v. 17| n. 1 | Ano 2019

Paloma Veridiane Dapper Universidade de Passo Fundo - UPF paloma_dapper@hotmail.com

Rafael Grenzel

Universidade de Passo Fundo - UPF rafaelgrenzel@hotmail.com

Jocias Maier Zanatta

Universidade Federal de Santa Maria - UFSM josk85@hotmail.com

\section{IMPLEMENTAÇÃO DE UMA ROTINA \\ DE MANUTENÇÃO PREVENTIVA EM ROLAMENTOS DE MOTORES \\ ELÉTRICOS UTILIZANDO A TERMOGRAFIA}

\section{RESUMO}

Os motores elétricos estão inseridos em diversos setores produtivos e representam o maior percentual de equipamentos rotativos de uma instalação, o que torna necessário uma rigorosa rotina de manutenção. Este trabalho técnico tem como objetivo analisar as atividades de manutenção preventiva que são executadas em motores elétricos instalados nos equipamentos de uma usina hidrelétrica e elaborar uma proposta para a implementação da manutenção preditiva através de inspeções termográficas em mancais do tipo rolamento. No decorrer do estudo foi realizado o levantamento da situação atual, elaborada proposta de rotina de manutenção, descrita a metodologia para execução, e por fim, os resultados potenciais com a implementação da rotina de manutenção.

Palavras-chave: Motores elétricos. Termografia. Manutenção preventiva.

\section{IMPLEMENTATION OF A PREVENTIVE MAINTENANCE ROUTINE IN ELECTRIC MOTOR BEARINGS USING THE THERMOGRAPHY}

\begin{abstract}
The electric motors are inserted in several productive sectors and represent the highest percentage of rotating equipment in an installation, which makes a strict maintenance routine necessary. This technical work has as objective to analyze the preventive maintenance activities that are performed on electric motors installed in the equipment of a hydroelectric plant and to elaborate a proposal for the implementation of the predictive maintenance through thermographic inspections in bearing type bearings. In the course of the study, the current situation was elaborated, a routine maintenance proposal was elaborated, the methodology for execution was described, and finally the potential results with the implementation of the maintenance routine.
\end{abstract}

Keywords: Electric motors. Thermography. Preventive maintenance. 


\section{INTRODUÇÃO}

Os motores elétricos estão inseridos em diversos setores produtivos e representam o maior percentual de equipamentos rotativos de uma instalação, por isso é importante ter uma estratégia de manutenção bem elaborada buscando mantê-los em perfeito estado de conservação para que possam desempenhar sua função requerida no processo.

Entre as áreas produtivas destacamos a área de geração de energia elétrica, onde a produção de energia é realizada através de usinas térmicas, hidrelétricas, nucleares e outras. Neste caso, os motores elétricos possuem funções relevantes que auxiliam no processo de produção de energia. Estão instalados de forma redundante em equipamentos como: bombas de injeção e circulação de óleo de resfriamento de mancais, bombas de pressurização de óleo de servomotores, compressores de ar, ventiladores e bombas de drenagem.

Neste contexto, é fundamental a utilização de mecanismos que auxiliam a melhoria continua da confiabilidade na operação dos equipamentos. Além da utilização da manutenção preventiva, efetuada em intervalos predeterminados, é necessário ter um acompanhamento dos parâmetros normais de operação dos equipamentos. Isso é obtido utilizando técnicas de manutenção preditiva.

Portanto, este trabalho técnico tem como objetivo analisar as atividades de manutenção preventiva que são executadas em motores elétricos instalados nos equipamentos de uma usina hidrelétrica e elaborar uma proposta para a implementação da manutenção preditiva através de inspeções termográficas em mancais do tipo rolamento. Esta proposta visa obter melhorias no planejamento e controle das atividades de manutenção.

\section{SITUAÇÃO ATUAL}

A gestão dos ativos da usina hidrelétrica é realizada através software SAP. A manutenção é gerenciada com a utilização do módulo de manutenção da planta (PM). Com este modulo é possível planejar, executar e controlar todos os serviços efetuados durante uma intervenção de manutenção. Nele é configurado um plano de manutenção que emite, em periodicidade definida, ordens de manutenção que serão programadas e executadas em determinados equipamentos.

Conforme o regime de operação dos equipamentos, o plano de manutenção nos motores elétricos da instalação contempla manutenções preventivas realizadas na periodicidade anual. As atividades executadas 
pelas equipes de manutenção são: inspeção visual, medição da resistência de isolamento, lubrificação e limpeza. Na inspeção visual é verificada a vibração excessiva, o alinhamento do acoplamento, a oxidação, as peças danificadas, o estado das vedações, o estado da conexão elétrica, o ruído anormal e outras. A medição da resistência de isolamento é realizada nos terminais do motor com o megômetro, onde é aplicada uma tensão de 500 volts e verificada as condições do material isolante no enrolamento do estator. A limpeza tem como objetivo manter a carcaça limpa, eliminando o acumulo de óleo ou pó na parte externa do motor. Quanto a lubrificação é realizada dependendo do tipo de rolamento aplicado.

As informações das anomalias encontradas, os valores da medição da resistência de isolamento e o tempo da execução de cada atividade são relatadas na ordem de serviço.

Os defeitos e as falhas são informadas em notas de anomalia, onde os operadores da instalação registram no modulo PM. A equipe de manutenção ao verificar a nota registrada, programa a ordem de manutenção e a intervenção com o intuito de normalizar o que foi relatado.

Em relação aos motores elétricos da instalação foi observado que no ano de 2016 foram emitidas 3 notificações de anomalias com a detecção de ruído anormal e 3 notificação de anomalia devido a atuação do relé de sobrecarga. No total de 6 notas, em 4 delas foi necessário a substituição dos rolamentos dos motores. $\mathrm{Na}$ análise das 4 notas de anomalias e as suas respectivas ordens de manutenção foi verificado que o tempo de reparo foi acima do normal e concluiu-se que o almoxarifado local não possuía todos os materiais necessários para o reparo corretivo.

\section{PROPOSTA DE ROTINA DE MANUTENÇÃO}

A situação atual demostra que é necessário utilizar técnicas de manutenção preditivas focada nos componentes que causaram a falha, neste caso, os rolamentos dos motores elétricos. Os rolamentos possuem a função de minimizar a fricção entre as peças móveis da máquina e suportar uma carga. A maioria dos rolamentos consiste em um anel interno, um anel externo, vários corpos rolantes (esferas ou rolos) e uma gaiola.

Conforme NSK, fabricante de rolamentos, apenas $3 \%$ de todos os rolamentos, de qualquer tipo e tamanho, chegam a atingir a vida útil para a qual foram projetados. Na maioria dos casos, os rolamentos falham devido a contaminação do lubrificante, falha no período ou processo de relubrificação, escolha incorreta do lubrificante, corrosão, fadiga do material, montagem e manuseio inadequado, dentre outras. Estas causas, aumentam o atrito 
deslizante entre os anéis e os corpos rolantes e tendo como consequência o sobreaquecimento na região do componente afetado.

Os limites de temperatura nos rolamentos variam com o modelo e o tipo de lubrificação adotada. É indicativo de anomalia em rolamentos, se o eixo do motor apresentar temperaturas próximas a $70^{\circ} \mathrm{C}$, ou se a temperatura do eixo for $20^{\circ} \mathrm{C}$ acima da temperatura da carcaça do mesmo.

Para o monitoramento da temperatura existem vários métodos de medição como: termômetros de contato, fitas indicadoras de temperatura, termômetros infravermelhos e termovisores. Para o nosso caso será utilizado o termovisor. Os termovisores são instrumentos utilizados para captar e processar as radiações térmicas, permitindo detectar e registrar as imagens térmicas e transformar as leituras em imagens de vídeo. Esse instrumento já é utilizado nas atividades de manutenção, especificamente em inspeção de possíveis defeitos de mau contato de conexões elétricas em painéis elétricos.

Embora o termovisor não seja capaz de ver o interior do motor, a temperatura da superfície externa é um indicador da temperatura interna. $\grave{A}$ medida que o esquenta por dentro, ele também esquenta na parte externa. Assim, um termógrafo experiente que possui conhecimento sobre motores elétricos pode utilizar as imagens térmicas para identificar condições tais como fluxo de ar inadequado, falha iminente de rolamentos, problemas no acoplamento do eixo e deterioração do isolamento do rotor ou do estator em um motor.

A figura 1 apresenta um caso de aquecimento elevado no mancal dianteiro do motor, onde o defeito resultou em sobrecarga e posterior o travamento do rolamento.

Figura 1 - Termograma demonstrando sobreaquecimento no mancal dianteiro do motor

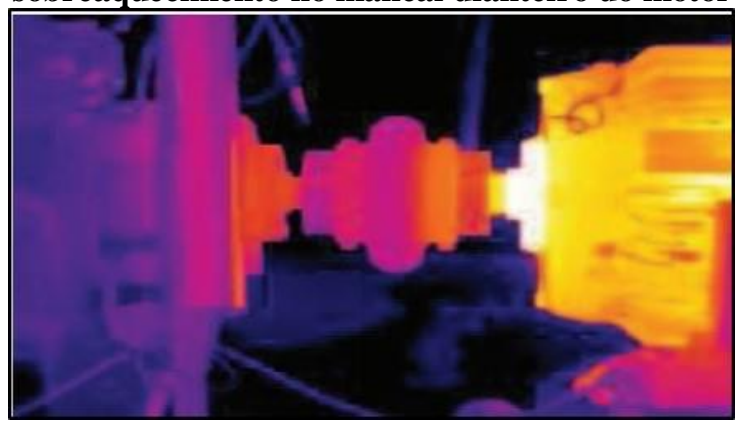

Fonte: Elaborado pelos autores, 2017

Portanto a proposta baseia em aplicar novas técnicas de manutenções preditivas em motores elétricos instalados em uma usina hidrelétrica. Inicialmente o monitoramento da temperatura de operação dos motores será realizada com um termovisor. A atividade será emitida através de ordens de manutenção na periodicidade definida pelo plano de manutenção. A execução do monitoramento será conforme a orientação de um procedimento de manutenção preditiva que será elaborado.

\section{METODOLOGIA}

O primeiro passo será buscar conhecer os motores instalados, ou seja, verificar as informações como temperatura 
máxima de operação, tipo de rolamentos instalados, regime de serviço e tempo de operação do equipamento.

Com as informações disponíveis será possível, na segunda etapa, definir dois níveis críticos de temperatura. Nível anormal, onde inicia-se a monitoração da temperatura em uma periodicidade curta até a data programada da intervenção ou até atingir o nível crítico. Nível crítico ou de emergência é quanto o motor chegou na sua temperatura limite de operação e é necessário realizar a intervenção da manutenção imediatamente.

A terceira etapa será destinada para a definição das periodicidades das inspeções termográficas em cada equipamento. A periodicidade poderá ser mais curta ou mais longa, dependendo da importância do equipamento na instalação, do regime de serviço e do tempo de operação do motor elétrico.

A elaboração do procedimento de manutenção preditiva nos motores será realizado na quarta fase, na qual deverá ser destacados os pontos relevantes na captura das imagens termográficas. Também nesta etapa poderá ser definido um modelo de relatório que será anexado na ordem de manutenção.

$\mathrm{O}$ treinamento da equipe de manutenção referente a execução da nova técnica de manutenção preventiva será realizada no quinto passo. Considerando que a manutenção já utiliza o termovisor em algumas atividades na instalação, o treinamento ficará relativo ao novo procedimento e os casos práticos de ocorrências de pontos de sobreaquecimento e seus respectivos defeitos ou falhas.

Na última fase de implementação será necessário realizar o cadastramento das atividades e o procedimento da inspeção termográfica do respectivo equipamento no plano de manutenção da usina hidrelétrica.

A figura 2 destaca as etapas para a implementação da manutenção preditiva com a utilização da câmera termográfica.

Figura 2 - Etapas da implementação da manutenção preditiva na instalação

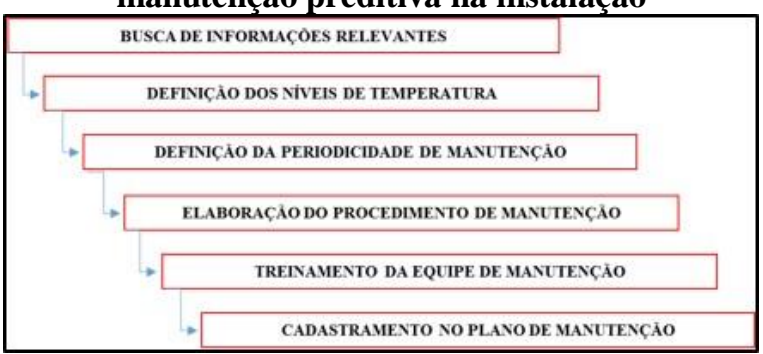

Fonte: Elaborado pelos autores, 2017

\section{RESULTADOS ESPERADOS}

Com a utilização do termovisor periodicamente na manutenção dos motores elétricos será possível detectar um defeito ou a iminência de uma falha precocemente. A tendência é que o defeito seja detectado em um tempo hábil para realizar a programação da manutenção e a intervenção, com todos os materiais necessários, no momento em que o equipamento estará disponível para efetuar reparo. 
A utilização da termografia, além da função especificada, poderá ser utilizada para detectar antecipadamente defeitos que apresentam o sobreaquecimento como consequência das seguintes causas: fluxo de ar inadequado, tensão desequilibradas, sobrecarga, defeito de isolamento, desalinhamento do eixo ou outros.

A técnica de manutenção preditiva adotada aumentará a vida útil dos motores elétricos. Conforme informação do fabricante de motores WEG, um aumento da ordem de $10^{\circ} \mathrm{C}$ na temperatura da isolação acima de sua classe térmica normalmente reduz sua vida útil pela metade.

Com isso, a tendência será reduzir as taxas de falhas e as atividades de manutenção corretiva. Tendo conhecimento do defeito antecipadamente será possível obter uma programação adequada de execução da manutenção, reduzindo o índice de tempo de reparo. Portanto, terá como consequência a redução do tempo de indisponibilidade do equipamento e com isso o aumento da confiabilidade do sistema de geração de energia elétrica.

\section{REFERÊNCIAS}

FLUKE. Guia de aplicações da termografia à manutenção industrial. Catálogo Técnico. Fluke, 2005.

ITTNER, E. R. Palestra: Aplicação da técnica da termografia em motores elétricos. SEMEQ, 2007.
NKS. Rollings Bearings. Catálogo técnico. NKS, 2006.

\section{PITOLI, M. H. Sistema portátil para} monitoramento e identificação de falhas em motores de indução trifásicos através da técnica da Análise da Assinatura Elétrica. Itajubá, 144p., 2013. Dissertação (Mestrado) - Universidade Federal de Itajubá.

\section{SKF. Termografia: Detecte pontos de} aquecimento, antes que estes causem problemas, 2017. Disponível em: < http://www.skf.com/br/products/conditionmonitoring/basic-condition-monitoringproducts/thermal-cameras/thermography/index.html > Acesso em 01 Setembro 2017.

SPANER, F. R. Técnicas preditivas de manutenção de máquinas rotativas. Rio de Janeiro, 240p., 2009. Monografia - Universidade Federal do Rio de Janeiro.

WEG. Manual Geral de Instalação, Operação e Manutenção de Motores Elétricos. Catálogo Técnico. Jaraguá do Sul:Weg, 2011.

WEG. W22: Motor Elétrico Trifásico. Catalogo Técnico. Jaraguá do Sul:Weg, 2010.

\section{Paloma Veridiane Dapper}

Engenheira Eletricista pela Universidade Regional do Noroeste do Estado do Rio Grande do Sul UNIJUI, Pós-Graduanda em Manutenção Industrial pela Universidade de Passo Fundo - UPF.

\section{Rafael Grenzel}

Engenheiro Eletricista pela Universidade Regional do Noroeste do Estado do Rio Grande do Sul UNIJUI, Pós-Graduando em Manutenção Industrial pela Universidade de Passo Fundo - UPF.

\footnotetext{
Jocias Maier Zanatta

Doutorando em Administração pela Universidade Federal de Santa Maria - UFSM, Mestre em Desenvolvimento pela Universidade Regional do Noroeste do Estado do Rio Grande do Sul - UNIJUI, Especialização em Gestão Financeira, Controladoria e Auditoria e Graduação em Administração pela Sociedade Educacional Três de Maio - SETREM. Professor e Administrador hospitalar.
} 
